\section{An Interferon-free Antiviral Regimen for HCV after Liver Transplantation}

\author{
Paul Y. Kwo, M.D., Parvez S. Mantry, M.D., Eoin Coakley, M.D., Helen S. Te, M.D., \\ Hugo E. Vargas, M.D., Robert Brown, Jr., M.D., M.P.H., Fredric Gordon, M.D., \\ Josh Levitsky, M.D., Norah A. Terrault, M.D., M.P.H., James R. Burton, Jr., M.D., \\ Wangang Xie, Ph.D., Carolyn Setze, M.S., Prajakta Badri, Ph.D., \\ Tami Pilot-Matias, Ph.D., Regis A. Vilchez, M.D., Ph.D., and Xavier Forns, M.D.
}

A BSTRACT

\section{BACKGROUND}

Hepatitis $\mathrm{C}$ virus (HCV) infection is the leading indication for liver transplantation worldwide, and interferon-containing regimens are associated with low response rates owing to treatment-limiting toxic effects in immunosuppressed liver-transplant recipients. We evaluated the interferon-free regimen of the NS5A inhibitor ombitasvir coformulated with the ritonavir-boosted protease inhibitor ABT-450 (ABT-450/r), the nonnucleoside NS5B polymerase inhibitor dasabuvir, and ribavirin in liver-transplant recipients with recurrent HCV genotype 1 infection.

\section{METHODS}

We enrolled 34 liver-transplant recipients with no fibrosis or mild fibrosis, who received ombitasvir-ABT-450/r (at a once-daily dose of $25 \mathrm{mg}$ of ombitasvir, $150 \mathrm{mg}$ of ABT-450, and $100 \mathrm{mg}$ of ritonavir), dasabuvir ( $250 \mathrm{mg}$ twice daily), and ribavirin for 24 weeks. Selection of the initial ribavirin dose and subsequent dose modifications for anemia were at the investigator's discretion. The primary efficacy end point was a sustained virologic response 12 weeks after the end of treatment.

\section{RESULTS}

Of the 34 study participants, 33 had a sustained virologic response at post-treatment weeks 12 and 24, for a rate of $97 \%$ (95\% confidence interval, 85 to 100). The most common adverse events were fatigue, headache, and cough. Five patients $(15 \%)$ required erythropoietin; no patient required blood transfusion. One patient discontinued the study drugs owing to adverse events after week 18 but had a sustained virologic response. Blood levels of calcineurin inhibitors were monitored, and dosages were modified to maintain therapeutic levels; no episode of graft rejection was observed during the study.

\section{CONCLUSIONS}

Treatment with the multitargeted regimen of ombitasvir-ABT-450/r and dasabuvir with ribavirin was associated with a low rate of serious adverse events and a high rate of sustained virologic response among liver-transplant recipients with recurrent HCV genotype 1 infection, a historically difficult-to-treat population. (Funded by AbbVie; CORAL-I ClinicalTrials.gov number, NCT01782495.)
From Indiana University, Indianapolis (P.Y.K.); the Liver Institute at Methodist Dallas, Dallas (P.S.M.); AbbVie, North Chicago, IL (E.C., W.X., C.S., P.B., T.P.-M., R.A.V.); University of Chicago Medical Center (H.S.T.) and Northwestern University Comprehensive Transplant Center (J.L.) - both in Chicago; Mayo Clinic, Phoenix, AZ (H.E.V.); Columbia University Medical Center, Center for Liver Disease and Transplantation, New York (R.B.); Lahey Hospital and Medical Center, Burlington, MA (F.G.); University of California, San Francisco, San Francisco (N.A.T.); University of Colorado Denver, Aurora (J.R.B.); and the Liver Unit, Hospital Clinic, Institut d'Investigacions Biomèdiques August $\mathrm{Pi}$ i Sunyer and Centro de Investigación Biomédica en Red de Enfermedades Hepáticas y Digestivas, University of Barcelona, Barcelona (X.F.). Address reprint requests to $\mathrm{Dr}$. Kwo at the Gastroenterology/Hepatology Division, Indiana University School of Medicine, 975 W. Walnut, IB 327, Indianapolis, IN 46202-5121, or at pkwo@iu.edu.

This article was published on November 11, 2014, at NEJM.org.

N Engl J Med 2014;371:2375-82. DOI: 10.1056/NEJMoa1408921 Copyright @ 2014 Massachusetts Medical Society. 
EPATITIS C VIRUS (HCV) PRESENTS A global health care challenge, with approximately 170 million people chronically infected. ${ }^{1}$ In 2012, approximately 24,000 liver transplantations were performed worldwide, with the largest proportion performed because of $\mathrm{HCV}$-induced liver disease. ${ }^{2,3}$ In the United States, more than $40 \%$ of registrants on the liver-transplant waiting list are infected with $\mathrm{HCV}^{3,4}$ After liver transplantation, recurrence of $\mathrm{HCV}$ infection is universal among recipients with viremia before transplantation. ${ }^{5,6}$ Fibrosis progression may be accelerated and HCV viral loads may be markedly increased in patients receiving post-transplantation immunosuppressive therapy as compared with patients not undergoing transplantation. ${ }^{7-9}$ Graft cirrhosis develops in 20 to $30 \%$ of $\mathrm{HCV}$-infected persons within 5 years after transplantation. ${ }^{10,11}$ As a result of these complications, HCV infection has become the leading cause of death in liver-transplant recipients. Patient and graft survival rates are markedly lower among HCV-infected patients than among those who received a liver transplant owing to cholestatic or alcohol-related liver disease. ${ }^{3,12,13}$

Successful clearance of HCV after liver transplantation can reduce the risk of subsequent HCV-related complications such as progression to cirrhosis and graft loss. ${ }^{13-16}$ The standard of care in the treatment of recurrent HCV genotype 1 infection after liver transplantation has been 48 weeks of peginterferon with ribavirin, though the response rates of 13 to $43 \%$ are generally lower than the rates of 40 to $52 \%$ among patients not undergoing transplantation, in part because of treatment-limiting toxic effects. ${ }^{8,15,17-19}$ In addition, interferon-based therapies can induce alloimmune graft injury, reducing patient and graft survival. ${ }^{16,20}$

Calcineurin inhibitors, such as tacrolimus and cyclosporine, are key components of most current post-transplantation immunosuppressive regimens. Long-term exposure to calcineurin inhibitors can progressively impair renal function, reducing ribavirin clearance. Consequently, augmented ribavirin exposure may increase the frequency and severity of ribavirin-associated hemolytic anemia, commonly requiring the use of hematopoietic growth factors, blood transfusion, or both. HCV treatment with a first-generation protease inhibitor, boceprevir or telaprevir, in combination with peginterferon and ribavirin results in a 20 to $71 \%$ response rate among livertransplant recipients; however, clinically significant side effects of these regimens, especially anemia and infections, were reported to limit their use. ${ }^{21-24}$ In addition, drug interactions between protease inhibitors and calcineurin inhibitors may require dose modification and monitoring. ${ }^{25,26}$

Phase 3 trials of an all-oral, interferon-free, direct-acting antiviral regimen of ombitasvir coformulated as a single tablet with ritonavirboosted ABT-450 (ABT-50/r) plus dasabuvir and ribavirin have shown high rates of sustained virologic response among patients with HCV genotype 1 infection, irrespective of prior treatment with peginterferon-ribavirin or the presence of cirrhosis. ${ }^{27-31}$ Ombitasvir is a potent NS5A inhibitor $^{32}$; ABT-450 is an NS3/4A protease inhibitor coadministered with ritonavir to increase peak, trough, and overall drug exposure, permitting once-daily dosing ${ }^{33}$; and dasabuvir is a nonnucleoside NS5B polymerase inhibitor. Next-generation interferon-free treatment regimens have not been extensively examined in transplant recipients with recurrent $\mathrm{HCV}$ genotype 1 infection. The CORAL-I trial assessed the safety and efficacy of ombitasvir-ABT-450/r and dasabuvir with ribavirin in this population of patients with an unmet need for safe and efficacious therapy.

\section{METHODS}

\section{PATIENTS}

Patients 18 to 70 years of age were eligible for the study if they had HCV genotype 1 infection (HCV RNA level $>10,000$ IU per milliliter) and had received a liver transplant at least 12 months before screening because of chronic HCV infection. Patients could have received interferon-based treatment for $\mathrm{HCV}$ infection before transplantation but not after transplantation. Eligible patients had no evidence of advanced fibrosis (Metavir score $\leq$ F2) on liver biopsy performed not more than 6 months before screening. A stable tacrolimus-based or cyclosporine-based immunosuppressive regimen was required, and glucocorticoids were permitted at a dose of no more than $5 \mathrm{mg}$ per day. Patients were excluded if they were coinfected with the human immunodeficiency virus or hepatitis $B$ virus or had undergone multiple-organ 
transplantation or liver retransplantation. Patients were enrolled from 10 transplantation centers in the United States and Spain between May and August 2013. Detailed eligibility criteria are provided in the Supplementary Appendix, available with the full text of this article at NEJM.org.

\section{STUDY DESIGN AND OVERSIGHT}

Patients in this phase 2, open-label trial received ombitasvir-ABT-450/r (at a once-daily dose of $25 \mathrm{mg}$ of ombitasvir, $150 \mathrm{mg}$ of ABT-450, and $100 \mathrm{mg}$ of ritonavir) and dasabuvir (250 $\mathrm{mg}$ twice daily) for 24 weeks. Ribavirin dosing was at the investigator's discretion because of the known risk of ribavirin-related hematologic toxic effects in transplant recipients. Patients were followed for up to 48 weeks after the treatment period (Fig. S1 in the Supplementary Appendix).

On the basis of simulations based on pharmacokinetic data from a phase 1 study that evaluated drug interaction between the study drugs and tacrolimus or cyclosporine, the following dosages of calcineurin inhibitors were recommended: for cyclosporine, one fifth of the pretreatment total daily dose, administered once daily; for tacrolimus, $0.5 \mathrm{mg}$ once weekly or $0.2 \mathrm{mg}$, where available, every 3 days. Modifications in tacrolimus or cyclosporine dosing during treatment were guided by scheduled testing of trough levels of calcineurin inhibitors. Details of the dosing of ribavirin and calcineurin inhibitors are provided in the Supplementary Appendix.

The study was conducted in accordance with International Conference on Harmonisation Guidelines for Good Clinical Practice, applicable regulations, and guidelines governing clinical-study conduct that have their origin in the Declaration of Helsinki. All patients provided written informed consent. The study was designed by the sponsor (AbbVie); the investigators and the sponsor jointly conducted the study and gathered the data. The sponsor conducted the data analyses. All authors signed a confidentiality agreement with the sponsor. The first draft of the manuscript was written by a sponsor-employed medical writer, with input from all the authors. All the authors made the decision to submit the manuscript for publication and vouch for the completeness and accuracy of the data and analyses and for the fidelity of the study to the protocol, which is available at NEJM.org.

\section{EFFICACY AND SAFETY ASSESSMENTS}

The primary efficacy end point was a sustained virologic response, defined as a plasma HCV RNA level of less than 25 IU per milliliter, 12 weeks after the end of treatment. Secondary assessments included the percentage of patients with a sustained virologic response at post-treatment week 24, virologic failure during treatment, and post-treatment relapse. A central laboratory used the COBAS TaqMan real-time reverse-transcriptase-polymerase-chain-reaction assay, version 2.0 (Roche), to test plasma samples for HCV RNA. Patients were monitored for clinical and laboratory evidence of adverse events at each study visit. Nonserious adverse events were recorded during the treatment period and until 30 days after the last dose. Serious adverse events were recorded from the time of informed consent until the end of the study. Details of plasma-sample collection, HCV RNA quantification, virologic-failure criteria, and resistance testing are provided in the Supplementary Appendix.

\section{STATISTICAL ANALYSIS}

Analyses of efficacy, safety, and baseline patient characteristics were performed on the intentionto-treat population, defined as all enrolled patients who received at least one dose of study drugs. The two-sided $95 \%$ confidence intervals for response rates were calculated with the use of the exact method based on the beta distribution. Patients with missing data at post-treatment week 12 or 24 , including those who dropped out, were counted as having had virologic failure. Descriptive statistics are provided, such as the number of observations, mean, and standard deviation for continuous variables and counts and percentages for discrete variables. SAS software for the UNIX operating system (SAS Institute) was used for all analyses.

\section{RESULTS}

\section{BASELINE DEMOGRAPHIC AND CLINICAL CHARACTERISTICS}

The CORAL-I study enrolled 34 patients, including 29 patients (85\%) with HCV genotype 1a infection. The median time since liver transplantation was 3.3 years. Overall, $76 \%$ of patients had a non-CC IL28B genotype, 71\% had previously been treated with peginterferon-ribavirin therapy, and 


\begin{tabular}{|c|c|}
\hline Characteristic & Value \\
\hline Male sex - no. (\%) & $27(79)$ \\
\hline \multicolumn{2}{|l|}{ Race - no. (\%)† } \\
\hline White & $29(85)$ \\
\hline Black & $4(12)$ \\
\hline Multiple & $1(3)$ \\
\hline Hispanic or Latino ethnic group — no. (\%) $\dagger$ & $6(18)$ \\
\hline Age $-y r$ & $59.6 \pm 6.6$ \\
\hline Body-mass indext & $29.7 \pm 4.5$ \\
\hline HCV genotype la - no. (\%) & $29(85)$ \\
\hline IL28B non-CC genotype - no. (\%) $\int$ & $26(76)$ \\
\hline HCV RNA - $\log _{10} I U / m l$ & $6.6 \pm 0.5$ \\
\hline $\begin{array}{l}\text { Lack of response to peginterferon-ribavirin treatment } \\
\text { before transplantation - no. (\%) }\end{array}$ & $24(71)$ \\
\hline \multicolumn{2}{|l|}{ Metavir fibrosis score — no. (\%) } \\
\hline F0 & $6(18)$ \\
\hline $\mathrm{Fl}$ & $13(38)$ \\
\hline $\mathrm{F} 2$ & $15(44)$ \\
\hline \multicolumn{2}{|l|}{ Time since liver transplantation - mo } \\
\hline Median & 39.5 \\
\hline Range & $12.9-136.4$ \\
\hline \multicolumn{2}{|l|}{ Primary immunosuppressive medication — no. (\%) } \\
\hline Tacrolimus & $29(85)$ \\
\hline Cyclosporine & $5(15)$ \\
\hline \multicolumn{2}{|l|}{ Other immunosuppressive medication — no. (\%) } \\
\hline Mycophenolic acid & $11(32)$ \\
\hline Prednisone & $2(6)$ \\
\hline Creatinine clearance $-\mathrm{ml} / \mathrm{min}$ & $90.5 \pm 26.4$ \\
\hline Creatinine $-\mathrm{mg} / \mathrm{dl} \|$ & $1.1 \pm 0.23$ \\
\hline Alkaline phosphatase $-U /$ liter & $109.3 \pm 40.4$ \\
\hline \multicolumn{2}{|l|}{ Liver enzymes — U/liter } \\
\hline Alanine aminotransferase & $78.9 \pm 62.7$ \\
\hline Aspartate aminotransferase & $63.9 \pm 43.5$ \\
\hline$\gamma$-Glutamyltransferase & $170.3 \pm 182.4$ \\
\hline
\end{tabular}

* Plus-minus values are means \pm SD. HCV denotes hepatitis $C$ virus.

$\uparrow$ Race and ethnic group were self-reported.

$t$ The body-mass index is the weight in kilograms divided by the square of the height in meters.

$\int$ The IL28B genotype was determined from DNA in peripheral blood obtained at baseline.

9 The Metavir fibrosis score (on a scale from F0 to F4, with F0 indicating no fibrosis and F4 fibrosis consistent with compensated cirrhosis) was based on a liver-biopsy specimen reviewed by a central pathologist.

$\|$ To convert the values for creatinine to micromoles per liter, multiply by 88.4 .
$85 \%$ were receiving a tacrolimus-based immunosuppressive regimen (Table 1).

\section{TREATMENT EFFICACY}

By week 4 of treatment, HCV RNA levels had decreased to less than 25 IU per milliliter in all 34 patients (Table 2); all the patients also had HCV RNA levels of less than 25 IU per milliliter at the end of treatment. With regard to the primary end point, 33 of 34 patients had a sustained virologic response at post-treatment week 12 , for a rate of $97 \%$ (95\% confidence interval [CI], 85 to 100). One patient did not have a sustained virologic response owing to a relapse on post-treatment day 3. No relapses occurred after post-treatment week 12; 33 of 34 patients (97\%) had a sustained virologic response at post-treatment week 24 . All 5 patients infected with genotype $1 \mathrm{~b}(100 \%)$ and 28 of 29 patients infected with genotype 1a (97\%) had a sustained virologic response. The remaining patient had resistance-associated variants R155K in NS3, M28T and Q30R in NS5A, and G554S in NS5B at the time of relapse, none of which were present at baseline. The NS3 variant Q80K was present in 11 of 29 patients (38\%) with HCV genotype 1a infection at baseline, including the patient with a relapse, who had had a null response to prior peginterferon-ribavirin therapy. Variants at resistance-associated positions in NS3, NS5A, and NS5B were each observed in at least 1 patient at baseline (Table S1 in the Supplementary Appendix).

\section{SAFETY}

Adverse events were common, though the majority were mild or moderate in severity (Table 3 ). The most common adverse events were fatigue, headache, and cough. None of the patients had graft rejection and there were no deaths during the study. One patient discontinued the study drugs after week 18 owing to rash, memory impairment, and anxiety. These events were assessed as having a reasonable possibility of being related to the study drugs; they were moderate in severity. This patient had a sustained virologic response 12 weeks after ending treatment prematurely. Two patients $(6 \%)$ had serious adverse events. Narratives on these two patients are provided in the Supplementary Appendix.

Grade 3 laboratory abnormalities were infrequent, and no grade 4 abnormalities were observed. Grade 3 elevations in the total bilirubin 
level were observed in two patients (6\%), occurring within the first 8 days of treatment in both. No patient had jaundice or scleral icterus. Elevations in the total bilirubin level predominantly reflected elevated values for indirect bilirubin, a finding consistent with inhibition of the organic anion-transporting protein $1 \mathrm{~B} 1$ by protease inhibitors. In one patient, total bilirubin levels were transiently elevated on day 92 , to a value that was more than 2 times the upper limit of the normal range (predominantly accounted for by an elevated indirect bilirubin level), and alanine aminotransferase levels were transiently elevated on day 85 , to a value that was more than 3 times the upper limit of the normal range. The values returned to the normal range on day 120 and on post-treatment day 4, respectively. Owing to persistent low-grade elevation of alanine aminotransferase levels during treatment, a liver biopsy was performed. The biopsy revealed markedly less necroinflammation than the prestudy biopsy, a finding consistent with a resolving HCV infection (Fig. S2 in the Supplementary Appendix). This patient had a sustained virologic response at post-treatment week 12 .

Grade 2 declines in hemoglobin levels ( 8 to $<10 \mathrm{~g}$ per deciliter) occurred in nine patients $(26 \%)$. One patient had a grade 3 decline in the hemoglobin level ( 6.5 to $<8.0$ g per deciliter) on day 15 and stopped ribavirin for 10 days. Erythropoietin was subsequently administered from day 26 to day 53; the hemoglobin level normalized by treatment day 42 .

\section{RIBAVIRIN DOSING}

The initial doses of ribavirin ranged from 400 to $1200 \mathrm{mg}$ daily (Table 4). The majority of patients received 600 or $800 \mathrm{mg}$ daily at study initiation (19 of 34 [56\%]) and also at the completion of treatment (23 of 34 [68\%]). Overall, 19 patients (56\%) had a modification in the ribavirin dose during treatment; 9 patients (26\%) had modifications owing to declines in hemoglobin levels. Five patients (15\%) received erythropoietin after detection of a nadir hemoglobin level of 7.6 to $9.1 \mathrm{~g}$ per deciliter. All 5 of these patients had initial ribavirin doses of 1000 to $1200 \mathrm{mg}$ daily, and all 5 had a sustained virologic response at post-treatment week 12. No patient received a blood transfusion.

\begin{tabular}{|c|c|c|}
\hline \multirow[t]{2}{*}{ Outcome } & \multicolumn{2}{|c|}{ Patients with Outcome } \\
\hline & no. & $\%(95 \% \mathrm{Cl})$ \\
\hline \multicolumn{3}{|l|}{ HCV RNA $<25 \mathrm{IU} / \mathrm{ml}$} \\
\hline \multicolumn{3}{|l|}{ During treatment period } \\
\hline At wk 4 & 34 & $100(90-100)$ \\
\hline At wk 24 & 34 & $100(90-100)$ \\
\hline \multicolumn{3}{|l|}{ After end of treatment } \\
\hline At wk 4 & 33 & $97(85-100)$ \\
\hline At wk 12 & 33 & $97(85-100)$ \\
\hline At wk 24 & 33 & $97(85-100)$ \\
\hline Virologic failure during treatment & 0 & $0(0-10)$ \\
\hline Relapse* & 1 & $3(0-15)$ \\
\hline
\end{tabular}

* Virologic relapse was defined as a confirmed HCV RNA level of 25 IU per milliliter or more between the final visit and 12 weeks after the last dose of study drugs among patients who had an HCV RNA level of less than 25 IU per milliliter at the final visit.

\section{DOSING OF CALCINEURIN INHIBITORS}

Modifications in the dose or dosing frequency of calcineurin inhibitors were made on the basis of blood levels of tacrolimus or cyclosporine. For most patients who received tacrolimus, $0.5-\mathrm{mg}$ and $0.2-\mathrm{mg}$ doses of tacrolimus were administered with a median dosing frequency of 10 days and 5 days, respectively. The geometric mean and range of trough blood concentrations of tacrolimus and cyclosporine during treatment were similar to those observed in the pretreatment period and were within the desired therapeutic range (Fig. S3 in the Supplementary Appendix).

The mean creatinine clearance was $90.5 \mathrm{ml}$ per minute at baseline and $85.9 \mathrm{ml}$ per minute at week 24 . No patient had a creatinine clearance of less than $50 \mathrm{ml}$ per minute during treatment. Five of 29 patients (17\%) had tacrolimus concentrations of more than $15.0 \mathrm{ng}$ per milliliter during the treatment period, although dosing errors accounted for the elevations in 4 of the 5 patients. Only one adverse event (mild rash) was reported in a patient with an elevated tacrolimus level. Shortly after treatment completion, 8 patients (28\%) had one or more tacrolimus measurements below the laboratory reference range; in all the patients, levels returned to the therapeutic range during subsequent follow-up, and no graft rejec- 


\section{Table 3. Adverse Events and Laboratory Abnormalities.}

\begin{tabular}{|c|c|}
\hline Event & $\begin{array}{c}\text { Patients } \\
\text { with Event } \\
\text { no. (\%) }\end{array}$ \\
\hline Any adverse event & $33(97)$ \\
\hline Any adverse event leading to discontinuation of study drugs & $1(3) *$ \\
\hline Serious adverse event $\dagger$ & $2(6)$ \\
\hline \multicolumn{2}{|l|}{ Common adverse events } \\
\hline Fatigue & $17(50)$ \\
\hline Headache & $15(44)$ \\
\hline Cough & $11(32)$ \\
\hline Anemia & $10(29)$ \\
\hline Diarrhea & $9(26)$ \\
\hline Insomnia & $9(26)$ \\
\hline Asthenia & $8(24)$ \\
\hline Nausea & $8(24)$ \\
\hline Muscle spasms & $7(21)$ \\
\hline Rash & $7(21)$ \\
\hline Back pain & $6(18)$ \\
\hline Dizziness & $6(18)$ \\
\hline Peripheral edema & $6(18)$ \\
\hline Rhinorrhea & $6(18)$ \\
\hline \multicolumn{2}{|l|}{ Grade 3 chemical or hematologic abnormality $\mathbb{~}$} \\
\hline Alanine aminotransferase & 0 \\
\hline Aspartate aminotransferase & 0 \\
\hline Alkaline phosphatase & 0 \\
\hline Total bilirubin & $2(6)$ \\
\hline Hemoglobin & $1(3)$ \\
\hline Creatinine clearance & 0 \\
\hline Creatinine & 0 \\
\hline
\end{tabular}

* One patient discontinued the study drugs owing to moderate rash, memory impairment, and anxiety after week 18 . This patient had a sustained virologic response 12 weeks after ending treatment prematurely.

$\uparrow$ A serious adverse event was defined as one that resulted in hospitalization or prolongation of hospitalization, persistent or clinically significant disability or incapacity, or death or that was life-threatening or required medical or surgical intervention to prevent a serious outcome.

$千$ Common adverse events are those that occurred in more than $15 \%$ of patients during the treatment period.

$\int$ The laboratory abnormalities listed here reflect post-baseline, post-nadir values. For alanine aminotransferase, aspartate aminotransferase, and alkaline phosphatase, a level of grade 3 was defined as a level that was more than 5 times and no more than 20 times the upper limit of the normal range. A total bilirubin level of grade 3 was defined as a level that was more than 3 times and no more than 10 times the upper limit of the normal range. A hemoglobin level of grade 3 was defined as a level of 6.5 to less than $8.0 \mathrm{~g}$ per deciliter. An abnormal creatinine clearance rate was defined as a rate of less than $50 \mathrm{ml}$ per minute. A creatinine level of grade 3 was defined as a level of 2.1 to less than $2.5 \mathrm{mg}$ per deciliter (186 to $<221 \mu \mathrm{mol}$ per liter).
Table 4. Dose of Ribavirin at Baseline and at the End of Treatment.

\begin{tabular}{lcc|}
\hline Daily Dose & $\begin{array}{c}\text { Baseline } \\
(\mathbf{N}=34)\end{array}$ & $\begin{array}{c}\text { Final } \\
\text { Treatment } \\
(\mathbf{N}=34)\end{array}$ \\
$400 \mathrm{mg}$ & $3(9)$ & no. (\%) \\
$600 \mathrm{mg}$ & $12(35)$ & $14(12)$ \\
$800 \mathrm{mg}$ & $7(21)$ & $9(26)$ \\
$1000 \mathrm{mg}$ & $4(12)$ & $5(15)$ \\
$1200 \mathrm{mg}$ & $8(24)$ & $2(6)$ \\
\hline
\end{tabular}

tion occurred. The suggested adjustments in the cyclosporine dose maintained trough concentrations within the therapeutic range.

Neither tacrolimus nor cyclosporine substantially altered the trough concentrations of ombitasvir, ABT-450, dasabuvir, or ribavirin. The trough concentrations of the study drugs were within the range observed in phase 2 and 3 studies of this regimen. ${ }^{27-31,34}$

\section{DISCUSSION}

Previous studies have shown that overall graft and patient survival rates are lower among livertransplant recipients with $\mathrm{HCV}$ infection than among transplant recipients without HCV infection, owing to universal reinfection and accelerated disease progression. No existing therapeutic regimens are approved for $\mathrm{HCV}$-infected livertransplant recipients. In the phase 2 CORAL-I trial of a 24-week, interferon-free, all-oral antiviral regimen for HCV genotype 1 infection, a rate of sustained virologic response of $97 \%$ ( $95 \% \mathrm{CI}$, 85 to 100 ) at post-treatment weeks 12 and 24 was observed among liver-transplant recipients with no fibrosis or mild fibrosis. Sustained virologic responses of 96 to $100 \%$ have been reported in phase 3 studies of 12 weeks of treatment with ombitasvir-ABT-450/r and dasabuvir with ribavirin in nonimmunosuppressed patients not undergoing liver transplantation. ${ }^{27-30}$

Studies of a first-generation protease inhibitor (boceprevir or telaprevir) in combination with peginterferon and ribavirin have shown lower rates of sustained virologic response (20 to $71 \%$ ) and high rates of toxic effects among immunosuppressed patients after transplantation, and some of these toxic effects can be life-threatening. ${ }^{21-24}$ In a phase 2 evaluation, treatment with 
the nucleotide polymerase inhibitor sofosbuvir and ribavirin for 24 weeks resulted in a sustained virologic response at post-treatment week 12 in 28 of 40 liver-transplant recipients $(70 \%){ }^{35}$ The patients included in these studies generally had advanced fibrosis, which may be associated with a decreased response rate.

Treatment of liver-transplant recipients with telaprevir or boceprevir plus peginterferon and ribavirin is associated with high rates of treatment discontinuation owing to adverse events. Side effects of these regimens result in frequent use of erythropoietin (in 77 to $100 \%$ of patients), modifications in the ribavirin dose (in 70 to $100 \%$ ), and blood transfusions (in 33 to $64 \%$ ) to manage anemia. ${ }^{21-24}$ Grade 3 and grade 4 laboratory abnormalities were each observed in $28 \%$ of patients receiving treatment with sofosbuvir and ribavirin, including hemoglobin levels of less than $8.0 \mathrm{mg}$ per deciliter in $20 \%$ of patients, ${ }^{35}$ although this study population included patients with cirrhosis, and such abnormalities may be observed more frequently in patients with cirrhosis than in those without cirrhosis.

In our study, doses of immunosuppressive calcineurin inhibitors were modified during the treatment period to maintain therapeutic levels. No deaths or episodes of graft rejection occurred in this population of difficult-to-cure transplant recipients with HCV infection. The rates of serious adverse events and study discontinuations due to adverse events observed in this small study were lower than the rates that have been observed with the interferon-based treatments that were the previous standard of care. ${ }^{36}$ Only one patient discontinued the study treatment owing to adverse events, and this patient had a sustained virologic response. In this immunosuppressed population, no new safety signals were identified, and events related to impairment of renal function and grade 3 laboratory abnormalities were similar to those observed in larger trials of this regimen involving patients not undergoing transplantation. ${ }^{27-31,34}$ However, this study was not large enough to accurately estimate rates of adverse events or to make comparisons with rates of adverse events in prior trials. No patient needed a blood transfusion; five patients $(15 \%)$ required erythropoietin, all of whom had initially received ribavirin at a total daily dose of 1000 or $1200 \mathrm{mg}$. These five patients were among the first study participants to receive the study drugs, and this observation was com- municated to the investigators with a suggestion to use a lower starting dose of ribavirin. Given the high response rate that was observed, regardless of the initial ribavirin dose, an initial dose of 600 to $800 \mathrm{mg}$ may provide sufficient therapeutic benefit and minimize the risk of severe anemia.

This study has limitations. Patients were excluded if they had advanced fibrosis (Metavir score $>$ F2) or had received interferon-based treatment after transplantation; thus, the study selected patients with cases of HCV infection that have historically been easier to treat than those characterized by advanced fibrosis. In addition, patients underwent transplantation at least 12 months before study initiation, so the study excluded those with early, aggressive forms of recurrent HCV infection (e.g., fibrosing cholestatic hepatitis) that can complicate treatment. Another limitation of the study was that immunosuppressive agents other than tacrolimus and cyclosporine were not evaluated; we assessed only these two agents because previous studies of interactions between drugs were restricted to these two agents.

In light of the worldwide organ shortage, a safe and effective antiviral regimen is needed for the treatment of $\mathrm{HCV}$-infected liver-transplant recipients, who have lower survival rates than other liver-transplant recipients. Treatment of recurrent HCV infection after liver transplantation is associated with improved outcomes in patients who have a sustained virologic response, ${ }^{13-15}$ including improvements in graft and patient survival, changes that may potentially reduce the demand for retransplantation. ${ }^{8}$ We found that the multitargeted regimen of ombitasvir-ABT-450/r and dasabuvir with ribavirin resulted in a $97 \%$ response rate among immunosuppressed liver-transplant recipients with recurrent HCV genotype 1 infection. This all-oral, interferon-free regimen was efficacious in eradicating HCV infection in a patient population who are at high risk for severe illness and death and for whom treatment options are currently limited.

Supported by AbbVie.

Disclosure forms provided by the authors are available with the full text of this article at NEJM.org.

We thank the trial participants, investigators, and coordinators who made this study possible; Anthony "Jake" Demetris, M.D., at the University of Pittsburgh and Christine Collins, Ph.D., Barbara McGovern, M.D., Rajeev Menon, Ph.D., Preethi Krishnan, Ph.D., Gretja Schnell, Ph.D., Rakesh L. Tripathi, M.S., Michelle Irvin, and Thomas Reisch, employees of AbbVie, for contributions to the study; and Douglas E. Dylla, Ph.D., of AbbVie for medical-writing support. 
REFERENCES

1. Hepatitis C: fact sheet no. 164. Geneva: World Health Organization, 2014 (http://www.who.int/mediacentre/factsheets/fs164/en).

2. World Health Organization, Spanish National Transplant Organization. Global observatory on donation and transplantation. 2012 (http://issuu.com/o-n-t/docs/ 2012ad).

3. Scientific Registry of Transplant Recipients 2012 annual data report. Rockville, MD: Health Resources and Services Administration, $2012 \quad$ (http://srtr .transplant.hrsa.gov/annual_ reports/2012/pdf/03_liver_13.pdf).

4. Biggins SW, Bambha KM, Terrault NA, et al. Projected future increase in aging hepatitis $\mathrm{C}$ virus-infected liver transplant candidates: a potential effect of hepatocellular carcinoma. Liver Transpl 2012;18:1471-8.

5. Berenguer M, Prieto M, Rayón JM, et al. Natural history of clinically compensated hepatitis C virus-related graft cirrhosis after liver transplantation. Hepatology 2000;32:852-8.

6. Wright TL, Donegan E, Hsu HH, et al. Recurrent and acquired hepatitis $\mathrm{C}$ viral infection in liver transplant recipients. Gastroenterology 1992;103:317-22.

7. Samuel D, Feray C. Recurrence of hepatitis C virus infection after liver transplantation. J Hepatol 1999;31:Suppl 1:217-21.

8. Gane EJ, Agarwal K. Directly acting antivirals (DAAs) for the treatment of chronic hepatitis $\mathrm{C}$ virus infection in liver transplant patients: "a flood of opportunity.” Am J Transplant 2014;14:994-1002. 9. Global Alert and Response (GAR) hepatitis C. Geneva: World Health Organization, 2014 (http://www.who.int/csr/ disease/hepatitis/whocdscsrlyo2003/en/ index5.html).

10. Berenguer M, Ferrell L, Watson J, et al. HCV-related fibrosis progression following liver transplantation: increase in recent years. J Hepatol 2000;32:673-84.

11. Prieto M, Berenguer M, Rayón JM, et al. High incidence of allograft cirrhosis in hepatitis $\mathrm{C}$ virus genotype $1 \mathrm{~b}$ infection following transplantation: relationship with rejection episodes. Hepatology 1999;29:250-6.

12. Terrault NA, Berenguer M. Treating hepatitis $\mathrm{C}$ infection in liver transplant recipients. Liver Transpl 2006;12:1192204.

13. Crespo G, Mariño Z, Navasa M, Forns $\mathrm{X}$. Viral hepatitis in liver transplantation. Gastroenterology 2012;142:1373-83.
14. Carrión JA, Navasa M, García-Retortillo $\mathrm{M}$, et al. Efficacy of antiviral therapy on hepatitis $\mathrm{C}$ recurrence after liver transplantation: a randomized controlled study. Gastroenterology 2007;132:174656.

15. Berenguer $M$, Palau A, Aguilera V Rayón JM, Juan FS, Prieto M. Clinical benefits of antiviral therapy in patients with recurrent hepatitis $\mathrm{C}$ following liver transplantation. Am J Transplant 2008;8:679-87.

16. Levitsky J, Fiel MI, Norvell JP, et al Risk for immune-mediated graft dysfunction in liver transplant recipients with recurrent $\mathrm{HCV}$ infection treated with pegylated interferon. Gastroenterology 2012;142:1132-9.

17. Gordon FD, Kwo P, Ghalib R, et al. Peginterferon- $\alpha-2 \mathrm{~b}$ and ribavirin for hepatitis C recurrence postorthotopic liver transplantation. J Clin Gastroenterol 2012;46:700-8.

18. Xiao N, Shi S, Zhuang H. A meta-analysis that compares the use of either peginterferon- $\alpha 2 \mathrm{a}$ or peginterferon- $\alpha 2 \mathrm{~b}$ plus ribavirin for $\mathrm{HCV}$ infection. Hepat Med 2010;2:99-109.

19. Ferenci P, Formann E, Laferl H, et al Randomized, double-blind, placebo-controlled study of peginterferon alfa-2a (40KD) plus ribavirin with or without amantadine in treatment-naive patients with chronic hepatitis $\mathrm{C}$ genotype 1 infection. J Hepatol 2006;44:275-82.

20. Selzner N, Guindi M, Renner EL, Berenguer M. Immune-mediated complications of the graft in interferon-treated hepatitis $\mathrm{C}$ positive liver transplant recipients. J Hepatol 2011;55:207-17.

21. Coilly A, Roche B, Dumortier J, et al Safety and efficacy of protease inhibitors to treat hepatitis $\mathrm{C}$ after liver transplantation: a multicenter experience. J Hepatol 2014;60:78-86.

22. Pungpapong S, Aqel BA, Koning L, et al. Multicenter experience using telaprevir or boceprevir with peginterferon and ribavirin to treat hepatitis $C$ genotype 1 after liver transplantation. Liver Transpl 2013; 19:690-700.

23. Saab S, Manne V, Bau S, et al. Boceprevir in liver transplant recipients. Liver Int 2014 March 26 (Epub ahead of print).

24. Burton JR Jr, O’Leary JG, Verna EC, et al. A US multicenter study of hepatitis C treatment of liver transplant recipients with protease-inhibitor triple therapy. J Hepatol 2014;61:508-14.

25. Garg V, van Heeswijk R, Lee JE, Alves
K, Nadkarni P, Luo X. Effect of telaprevir on the pharmacokinetics of cyclosporine and tacrolimus. Hepatology 2011;54:20-7. 26. Charlton M. Telaprevir, boceprevir, cytochrome P450 and immunosuppressive agents - a potentially lethal cocktail. Hepatology 2011;54:3-5.

27. Feld JJ, Kowdley KV, Coakley E, et al. Treatment of HCV with ABT-450/r-ombitasvir and dasabuvir with ribavirin. N Engl J Med 2014;370:1594-603.

28. Zeuzem S, Jacobson IM, Baykal T, et al. Retreatment of HCV with ABT-450/rombitasvir and dasabuvir with ribavirin. N Engl J Med 2014;370:1604-14.

29. Ferenci P, Bernstein D, Lalezari J, et al. ABT-450/r-ombitasvir and dasabuvir with or without ribavirin for HCV. N Engl J Med 2014;370:1983-92.

30. Andreone P, Colombo MG, Enejosa JV, et al. ABT-450, ritonavir, ombitasvir, and dasabuvir achieves $97 \%$ and $100 \%$ sustained virologic response with or without ribavirin in treatment-experienced patients with $\mathrm{HCV}$ genotype $1 \mathrm{~b}$ infection. Gastroenterology 2014;147:359-65.

31. Poordad F, Hezode C, Trinh R, et al. ABT-450/r-ombitasvir and dasabuvir with ribavirin for hepatitis $\mathrm{C}$ with cirrhosis. N Engl J Med 2014;370:1973-82.

32. Lawitz E, Marbury T, Campbell A, et al. Safety and antiviral activity of ABT-267, a novel NS5A inhibitor, during 3-day monotherapy: first study in HCV genotype-1 (GT1)-infected treatment-naive subjects. J Hepatol 2012;56:Suppl:S469s470.

33. Menon RM, Klein CE, Lawal AA, et al. Pharmacokinetics and tolerability of the HCV protease inhibitor ABT-450 following single ascending doses in healthy adult volunteers with and without ritonavir. Global Antiviral Journal 2009;5:Suppl 1:53.

34. Kowdley KV, Lawitz E, Poordad F, et al. Phase $2 b$ trial of interferon-free therapy for hepatitis C virus genotype 1 . N Engl J Med 2014;370:222-32.

35. Samuel D, Charlton M, Gane E, et al. Sofosbuvir and ribavirin for the treatment of recurrent hepatitis $\mathrm{C}$ infection after liver transplantation: results of a prospective, multicenter Study. J Hepatol 2014;60: Suppl:S26.

36. Lens S, Gambato $M$, Londoño $M C$, Forns X. Interferon-free regimens in the liver-transplant setting. Semin Liver Dis 2014;34:58-71.

Copyright (C) 2014 Massachusetts Medical Society. 